\title{
Effects of Surface Roughness on the Behavior of Interface between Old and New Deck Slabs Under Concentrated Load
}

\author{
Fakhruddin ${ }^{1, *}$, Junichiro $\mathrm{Niwa}^{2}$, Rudy Djamaluddin ${ }^{3}$, and Rita Irmawaty \\ ${ }^{1}$ Lecturer, Department of Civil Engineering, Hasanuddin University, Indonesia \\ ${ }^{2}$ Professor, Department of Civil Engineering, Tokyo Institute of Technology, Japan \\ ${ }^{3}$ Professor, Department of Civil Engineering, Hasanuddin University, Indonesia \\ ${ }^{4}$ Associate Professor, Department of Civil Engineering, Hasanuddin University, Indonesia
}

\begin{abstract}
Experimental and analytical studies on the behavior of interface between old and new deck slabs were investigated in this study. The test was performed to represent a bridge widening method that has been developed in Japan. Therefore, each specimen consist of the old and new deck slabs. The connection between those deck slabs was varied into a rough and smooth surface. Before testing, the slabs were prestressed using unbonded PC rods which amount of 1.0 MPa. The result of this study indicated that the difference in the level of roughness does not provide a significant effect on the ultimate capacity. Remarkable effects were only observed on crack pattern, deflection, and joint opening behavior. To validate the experiments, the ultimate capacity of experiment was compared with the predicted shear capacity obtained from JSCE Specification and $f i b$ Model Code. In the guidelines, the area of the interface is assumed as the total area of the interface. However, such assumption cannot be used in this study. Therefore, the effective area of the interface obtained from FEM analysis was proposed in this study. Eventually, by using the proposed effective area of the interface, the calculated results showed that all guidelines provide a good lower limit to predict the ultimate capacity of the deck slabs.
\end{abstract}

\section{Introduction}

The new prestressed concrete (PC) box girder widening technique has been proposed by some researchers in Japan [1]. The structural members of this technique consist of the precast rib, precast PC slab, and cast-inplace new deck slab as shown in Fig. 1. Full details of this new technique are reported by Niwa et al. [2].

In this method, the shear-transfer strength between the old and new deck slabs is achieved through the external prestressing force, and through the rebars extending from the old deck slabs to the new deck slab. Therefore, the behavior of the interface must be investigated experimentally and analytically.

Several tests have been performed by many researchers [3-9] to examine the behavior of the interface by conducting the direct-shear test and push-out test. The results indicated that the ultimate shear strength of the interface is determined by the strength of concrete, roughness degree and friction coefficient, and the normal compressive stress can increase the ultimate shear strength. It is also reported that the failure mode is a shear failure of the interface between the old and new concretes. Nevertheless, literature information concerning the behavior of the interface subjected to concentrated load was view.
Therefore, this study aims to investigate the behavior of the interface between the old and new deck slabs subjected to concentrated load. The parameter was the roughness degree of the interface which was varied into rough and smooth surface. The crack pattern, load-

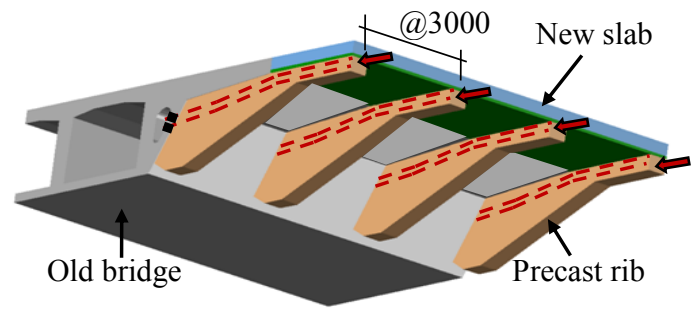

(a) Isometric view

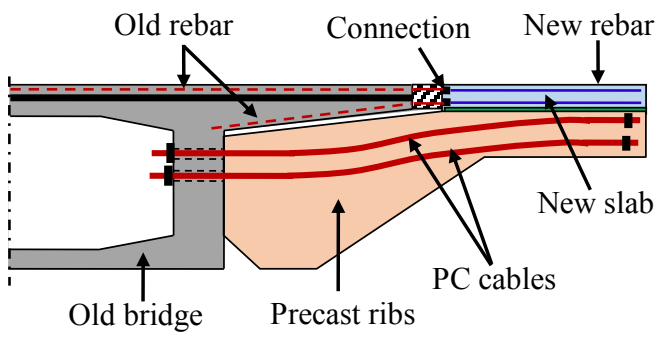

(b) Cross-section

Fig. 1. The new prestressed concrete (PC) box girder widening technique

\footnotetext{
* Corresponding author: fakhruddin@,unhas.ac.id and fakhrud.civil05@gmail.com
} 
displacement response, joint opening, ultimate capacity was examined. Finally, the experimental ultimate capacities were compared with those given by JSCE Specification [10] and fib Model Code 2010 [11].

\section{Experimental programs}

\subsection{Test specimens}

Figure 2 shows the details of the specimens. The slabs were scaled down according to half scale model with the geometrical parameters were $1500 \mathrm{~mm}$ long, $1225 \mathrm{~mm}$ wide and $100 \mathrm{~mm}$ thick. Each specimen consists of two parts and is cast at different times. The old slab is cast first followed by the new slab after seven days. The surface roughness was varied into rough (SL-P1.0) and smooth surface (SL-Smooth). To reproduce the rough surface, the old slab was intentionally roughened by using the retarder at the day before casting and spraying with high-pressure water after de-molding. Meanwhile, to reproduce the smooth surface, new concrete was cast directly against old concrete without roughness treatment.

\subsection{Material properties}

The compressive strength of the old and new deck slabs was $50 \mathrm{MPa}$. The compressive strength $\left(f_{c}^{\prime}\right)$ and splitting tensile $\left(f_{t}\right)$ tests were conducted on the day of slab testing and the results are listed in Table 1. The D16 rebars $\left(A_{s}=198.6 \mathrm{~mm}^{2}\right)$ and D10 rebars $\left(A_{s}=71.33 \mathrm{~mm}^{2}\right)$ having yield strength of $386.0 \mathrm{MPa}$ and $392.8 \mathrm{MPa}$ were used in the upper and lower longitudinal rebars, respectively

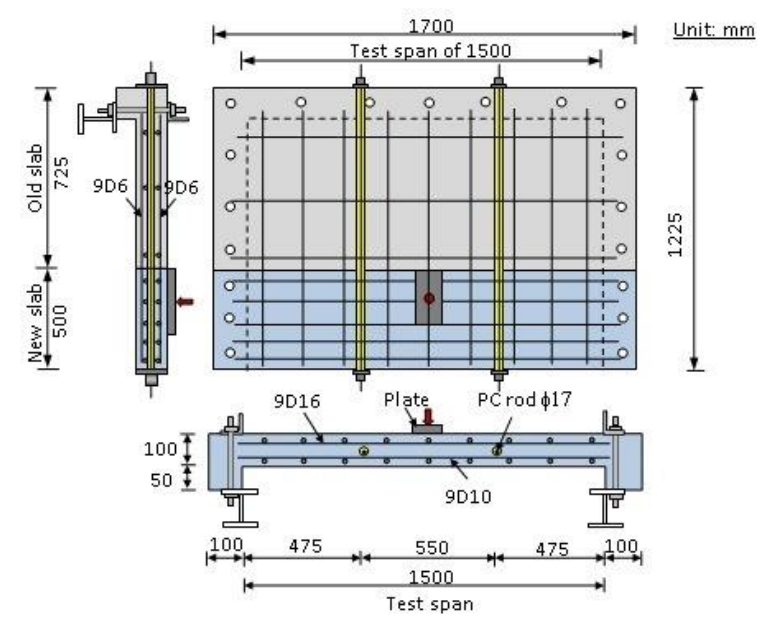

Fig. 2. Deck slab layout and reinforcement details.

Table 1. Deck slab layout and reinforcement details.

\begin{tabular}{|c|c|c|c|c|c|}
\hline \multirow{2}{*}{ Specimen } & \multirow{2}{*}{$\begin{array}{c}\sigma_{i} \\
(\mathrm{MPa})\end{array}$} & \multicolumn{2}{|c|}{$f_{c}^{\prime}(\mathrm{MPa})$} & \multicolumn{2}{c|}{$f_{t}(\mathrm{MPa})$} \\
\cline { 3 - 6 } & & $\begin{array}{c}\text { Old } \\
\text { slab }\end{array}$ & $\begin{array}{c}\text { New } \\
\text { slab }\end{array}$ & $\begin{array}{c}\text { Old } \\
\text { slab }\end{array}$ & $\begin{array}{c}\text { New } \\
\text { slab }\end{array}$ \\
\hline SL-P1.0 & \multirow{2}{*}{1.0} & 52.4 & 47.2 & 3.8 & 3.4 \\
\cline { 1 - 5 } SL-Smooth & 53.4 & 56.5 & 3.7 & 3.9 \\
\hline
\end{tabular}

$\sigma_{i:}$ initial prestress level at the interface between the old and new deck slabs; $f_{c}$ ': compressive strength of concrete and $f_{t}$ : tensile strength of concrete
(Fig. 2). Meanwhile, the D6 rebars $\left(A_{s}=31.67 \mathrm{~mm}^{2}\right)$ having yield strength of $345.0 \mathrm{MPa}$ were used in the upper and lower transverse rebars, respectively (Fig. 2). Prestressing rod (PC rod) with diameter of $17 \mathrm{~mm}\left(A_{s}=\right.$ $346.19 \mathrm{~mm}^{2}$ ) and yield strength of $1171 \mathrm{MPa}$ was used to introduce the prestresing force. The PC sheath with the inner diameter of $31 \mathrm{~mm}$ was installed inside the concrete to pass through the PC rod. The space remaining inside the $\mathrm{PC}$ sheath was around $10 \mathrm{~mm}$ and it was sufficient to prevent the friction between the PC rod and concrete during the loading tests.

\subsection{Procedures of fabrication}

Figure 3 illustrates the procedures of fabrication. First, the formwork was fabricated and subsequently, the PC sheet and the reinforcement were arranged into the formwork (Fig. 3a). To obtain the rough surface, the wooden formwork of the old deck slab was coated using the retarder on the day before casting (Fig. 3b). Subsequently, the old deck slab part was cast as shown in Fig. 3c. After de-molding, the concrete surface was sprayed with high pressure water to remove the outer sand and anhydrate mortar Fig. 3d. In the next step, the reinforcement for the new deck slabs was arranged ((Fig. 3e)). Then, the new deck slab part was cast as shown in Fig. 3f.

\subsection{Instrumentation and test setup}

Figure 4 shows the location of the transducers and $\pi$ gauges. Transducers were used to measure the deflections beneath the deck slabs and $\pi$-gauges were used to measure the joint opening, especially under the

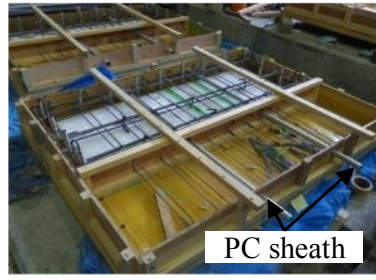

a. Formwork and rebars

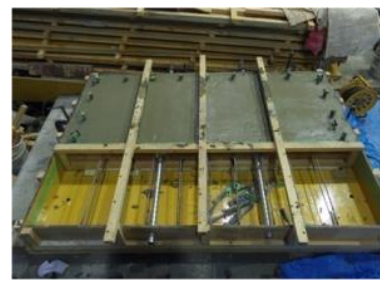

c. Casting old deck slab

e. Rebars for new deck

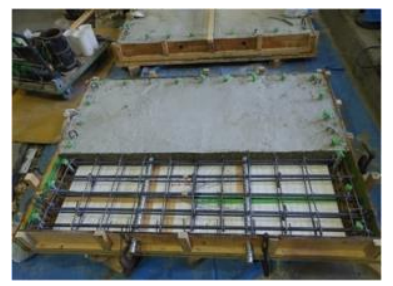

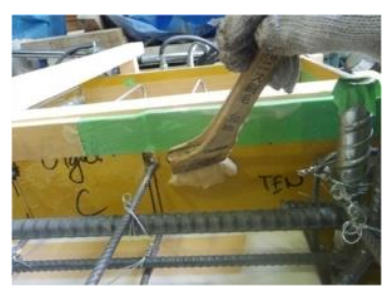

b. Coating with retarder

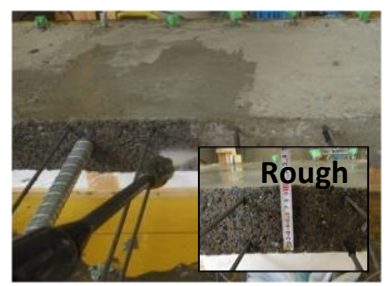

d. Spraying water (rough)

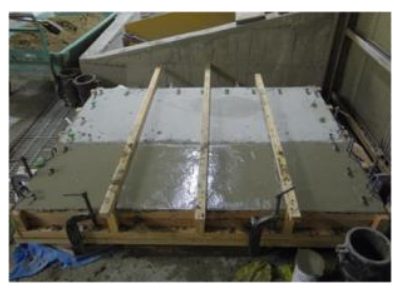

f. Casting new deck slab
Fig. 3. Fabrication procedures of specimen 


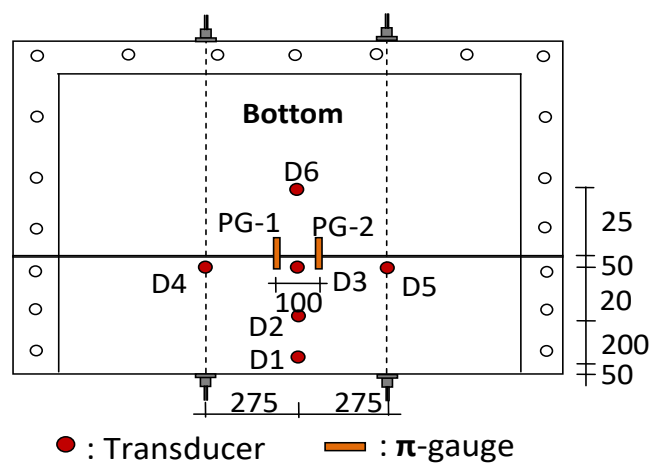

Fig. 4. Location of transducers and $\pi$-gauges

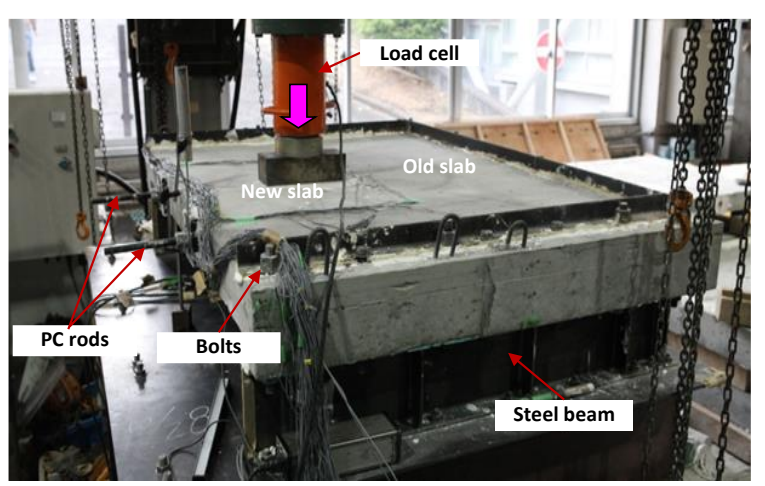

Fig. 5. Test setup.

loading. Several strain gauges were also attached to the steel bars and PC rods.

Before testing, the slabs were prestressed using two unbonded PC rods and anchored at both ends of the slabs. After that, the slabs were restrained at the supporting steel beams and fixed with high strength steel bolts along the three edges as shown in Fig. 5. Similar test methods were conducted by previous researchers $[12,13]$. To achieve level surfaces, a thin layer of gypsum was used at the interface between the supports and the slab. After that, a static loading was applied by a hydraulic actuator with a maximum load of $3000 \mathrm{kN}$. The magnitude of the load was measured using a load cell and the data was recorded using data logger. The loading surface was $100 \times 250 \mathrm{~mm}$ rectangular loading plate. This loaded area is determined from the half-scale of the footprint for the truck single-wheel load of $100 \mathrm{kN}$ as specified by AASHTO LRFD 2007 [14].

\section{Results and discussions}

\subsection{Crack pattern}

Figures 6a and b shows the crack patterns of SL-P1.0 (rough) and SL-Smooth (smooth). The solid and dashed lines express the cracks on the top and bottom surfaces of the slabs, respectively. Generally, the crack pattern consisted of the flexural cracks, tensile cracks and crack at the interface. However, two significant differences were observed in this study. These differences were explained below.

First is the propagation of the flexural cracks on the bottom surface of the slab. In SL-P1.0 with rough

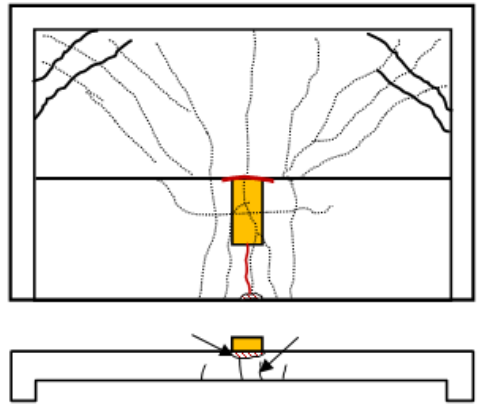

a. SL-P1.0 (Rough)

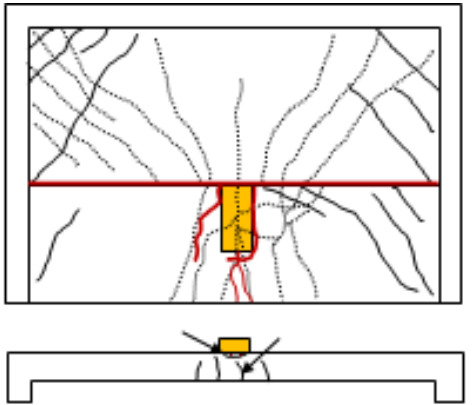

b. SL-Smooth

Fig. 6. Fabrication procedures of specimen

surface, the flexural cracks can pass through the interface and continued to the new deck slab. On the other hand, in SL-Smooth with smooth surface, the flexural cracks in the old deck slab cannot pass through the interface. Second is the propagation of the crack at the interface. In SL-P1.0 (rough surface), the crack at the interface only concentrated around the loading point (Fig. 6a). But in SL-Smooth (smooth surface), the crack at the interface extended from the loading point to the entire length of the interface (Fig. 6b).

Therefore, it was highlighted that the propagation of the crack at the interface was highly affected by the roughness of the interface. This is because the rough surface had sufficient shear strength and on the other hand, the smooth surface had not sufficient shear strength to transfer load to the adjacent deck slab (new deck slab).

\subsection{Load-deflection responses}

The load-deflection responses are shown in Fig. 7. The displacements reported in this figure are the measured deflection under the loading point (D3 transducer in Fig. 4). It was observed that the stiffness of the loaddeflection curves did not decrease significantly after the first joint opening occurred $\left(P_{c r}\right)$. A significant difference was observed at the load of $125 \mathrm{kN}$ because the shear slip occurred in SL-Smooth. At failure, SLSmooth showed higher deflection $(27.7 \mathrm{~mm})$ compared with that of SL-P1.0 (22.9 $\mathrm{mm})$. Since the smooth surface in SL-Smooth, the interface produced smaller friction stress and aggregate interlock to resist the interface shear stress due to the applied load. 


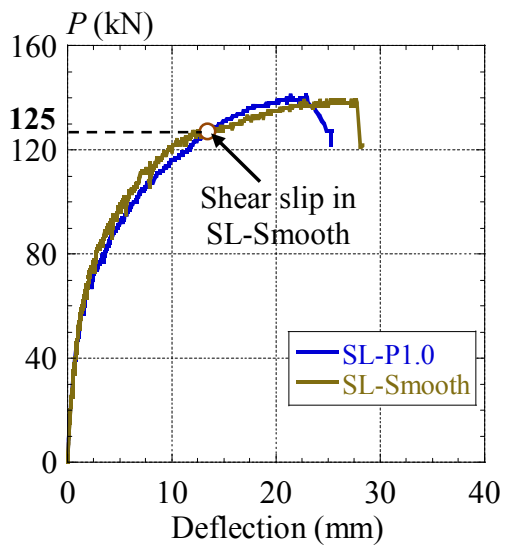

Fig. 7. Load-deflection curves (D3 transducer).

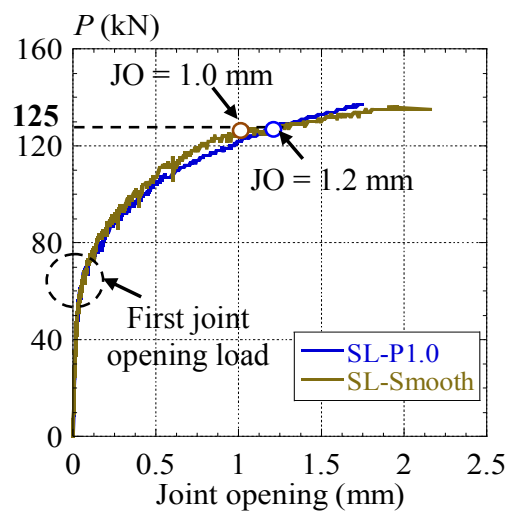

Fig. 8. Load-deflection curves (D3 transducer).

\subsection{Load-joint opening responses}

The responses of load versus joint opening are presented in Fig. 8. It was seen that the joint opening of SL-P1.0 was almost similar with SL-Smooth until the first joint opening load $\left(P_{c r}\right)$, which occurred at $63 \mathrm{kN}$ and $55 \mathrm{kN}$, respectively. Beyond the $P_{c r}$, the difference between SLP1.0 and SL-Smooth could be clearly observed, whereas the magnitude of the joint opening of SL-P1.0 at the same load level was greater than that of SL-Smooth. For instance, at the load of $125 \mathrm{kN}$, the measured joint openings in SL-P1.0 and SL-Smooth were $1.2 \mathrm{~mm}$ and $1.0 \mathrm{~mm}$, respectively (Fig. 8). This is because the joint opening in SL-P1.0 was concentrated around the loading point (Fig. 6a) while in SL-Smooth, the joint opening was propagated into the whole of the interface (Fig. 6b).

To explain the above behavior, the responses of loadconcrete strain at the top fiber of the interface are presented in Fig. 9. The strain gauge was attached perpendicular to the interface, exactly at $137.5 \mathrm{~mm}$ from the slab center. Obviously, the top fiber of the interface tended to be compressed from the beginning of the load up to $125 \mathrm{kN}$. After that, the shear resisting mechanism of the interface significantly changed. When the interface became rough, the top fiber of the interface was still able to form the compression fiber until the failure. However, when the interface became smooth, the compressive force gradually reduced and turned into tension. Hence, the joint opening propagated along the smooth interface and finally produced a significant shear slip at the interface as it was shown in Fig. 10.

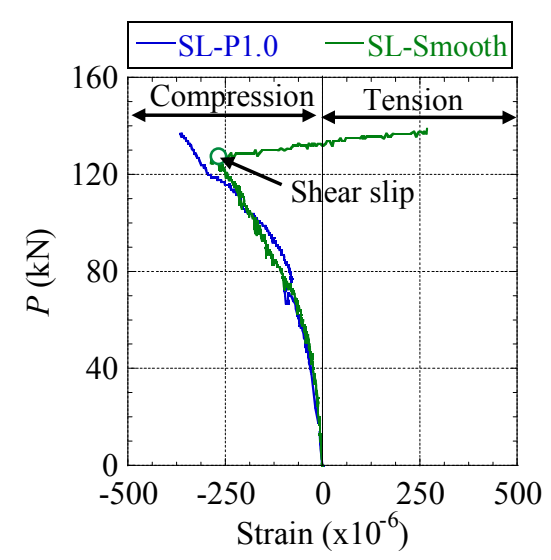

Fig. 9. Behavior of concrete gauge at top surface

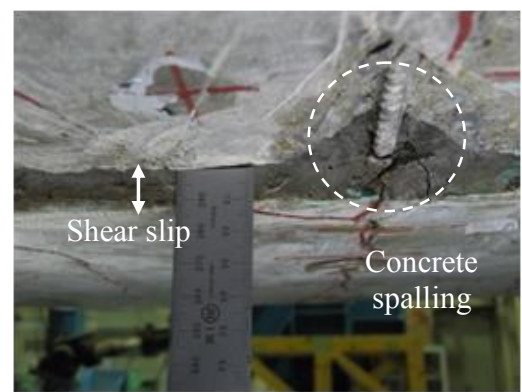

Fig. 10. Shear slips in SL-Smooth (bottom surface).

\subsection{Ultimate capacity and failure mode}

All the slabs failed in shear failure of the interface between the old and new deck slabs. The ultimate capacities of SL-P1.0 and SL-Smooth were $141 \mathrm{kN}$ and $139 \mathrm{kN}$, respectively. To make it independent of the concrete strength, the obtained ultimate capacities were divided by the square root of concrete compressive strength $\left(P_{u} / \sqrt{f_{c}^{\prime}}\right) . P_{u}$ is the ultimate capacity $(\mathrm{kN})$ and $f_{c}^{\prime}$ is the concrete compressive strength $\left(\mathrm{N} / \mathrm{mm}^{2}\right)$. Thus, $P_{u} / \sqrt{f_{c}^{\prime}}$ of SL-P1.0 and SL-Smooth were 18.8 and 18.7, respectively (Fig. 11). It indicated that the effect of the surface roughness on the ultimate capacity was very slight.

The above results were contradicted by the general agreement for the concrete-to-concrete interface under direct-shear test which was conduicted by Randl [15]

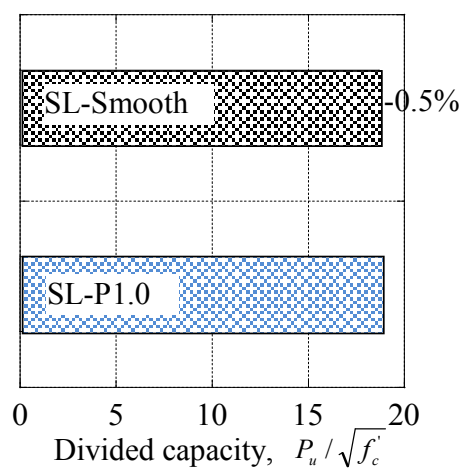

Fig. 11. Ultimate capacity normalized with concrete strength. 


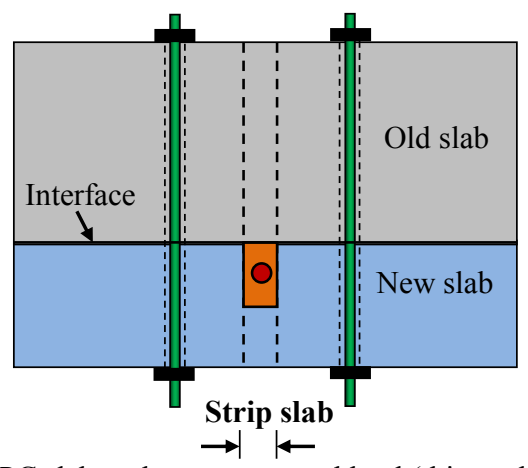

a. PC slab under concentrated load (this study)
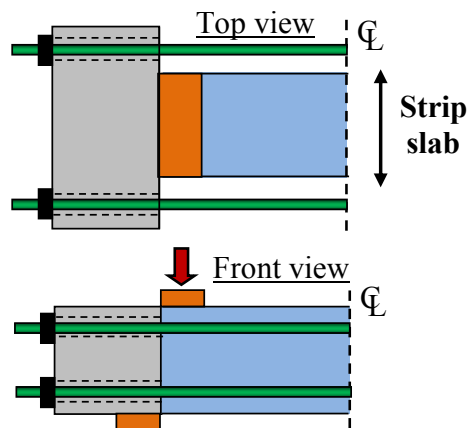

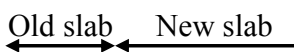

b. Direct shear test (Niwa et al. 2016)

Fig. 12. Behavior of PC slab under concentrated load vs. direct shear test.

and Niwa et al. [2]. In that study, they concluded that the ultimate capacity increases significantly as the degree of roughness of a particular surface increases. The different results in this study will be explained as follows. For the PC deck slab subjected to a concentrated load (Fig. 12a), the width of the loading plate was much smaller than the total width of the interface. Hence, the compressive stress will be concentrated only in the particular part of the interface, exactly around the loading point. Moreover, due to the two-way slab interaction, the contribution of the loaded slab (new slab) on the ultimate capacity is also significant. Therefore, in the case of PC deck slab under a concentrated load, the ultimate capacity will be determined by two factors, the one from the shear capacity of the interface and the other from the flexural capacity of the new slab (loaded panel). On the other hand, in the case of the direct-shear test in Fig. 12b, the strip specimen representing the deck slab section will be used. It is seen in this figure that the width of the loading point is equal to the total width of the interface. The shear stress will be localized at the total area of the interface and consequently, the interface becomes the weakest point than the loaded slab (new slab). Therefore, in the case of the direct-shear test, the ultimate capacity can be determined by the ultimate capacity of the interface between the old and new slabs.

\section{Comparison experiment guidelines}

and

Since the experimental failure mode was a shear failure at the interface, the experimental shear capacities were compared with predicted shear capacities using JSCE Specification 2007 [10] and fib Model Code 2010 [11].

Based on JSCE Specification, the design capacity for shear transfer $P_{u}$ was computed using the following equations:

$$
\begin{gathered}
P_{u}=\left(\tau_{c}+p \tau_{s} \sin ^{2} \theta-\alpha p f_{y} \sin \theta \cos \theta\right) A_{c}+P_{k} \\
\tau_{c}=\mu f_{c}^{\prime b}\left(\alpha p f_{y}-\sigma_{n}\right)^{1-b} \\
\tau_{s}=0.08 f_{y} / \alpha \\
\alpha=0.75\left\{1-10\left(p-1.7 \sigma_{n} / f_{y}\right)\right\}
\end{gathered}
$$

where $p$ : reinforcement ratio $\left(p=A_{s} / A_{c}\right), A_{s}$ : area of reinforcement crossing the interface, $A_{c}$ : area of the interface, $\theta$ : angle between interface and reinforcement at the interface $\left(\theta=90^{\circ}\right.$ in this study), $f_{y}$ : yield strength of reinforcement, $P_{k}$ : shear capacity of shear key $\left(P_{k}=0\right.$ in this study), $\mu$ : coefficient of friction $(\mu=0.45$ in this study), $\sigma_{n}$ : average normal compressive stress acting on the interface, and $b$ : coefficient representing configuration of planes (For segmental joint, $b=0.5$ ).

In $f i b \mathrm{MC} 2010$, the shear resistance of the interface $\tau_{u}$ was evaluated by the following equation:

$$
\tau_{u}=\underbrace{\tau_{c}}_{\text {Interlock }}+\underbrace{\mu\left(\sigma_{n}+\kappa_{1} \rho f_{y}\right)}_{\text {Friction }}+\underbrace{\kappa_{2} \rho \sqrt{f_{c, \text { cube }} f_{y}}}_{\text {Dowel action }} \leq \beta v f_{c, \text { cube }}
$$

where $\tau_{c}$ : interlocking strength $(0.5-1.5$ for smooth, and 1.5-2.5 for rough), $\mu$ : coefficient of friction (0.5-0.7 for smooth and 0.7-1.0 for rough), $\kappa_{1}$ : interaction factor of reinforcement due to simultaneous bending of rebars $(0.5), \kappa_{2}$ : interaction factor for the dowel action ( 0.9 for smooth and 1.1 for rough), $f_{c, \text { cube: }}$ cube compressive strength $\left(f_{c, \text { cube }}=f_{c, \text { cylinder }} / 0.85\right), \beta$ : coefficient allowing for angle of diagonal concrete strut ( 0.5 for smooth and 0.4 for rough), $v$ : reduction factor for strength of

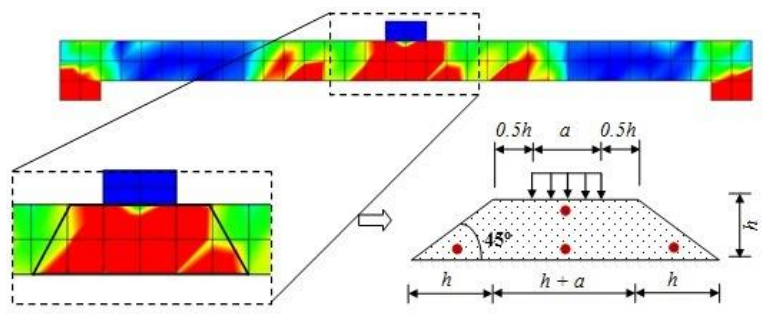

a. SL-P1.0 (rough)

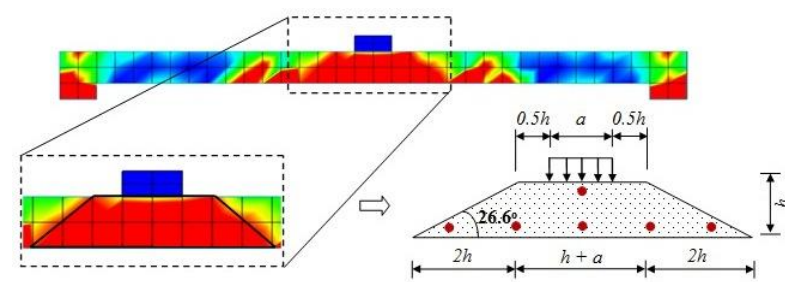

b. SL-Smooth (smooth)

$h$ : thickness of the slab; $a$ : length of rectangular concentrated loading; $\bullet$ : transverse rebars which have yielded at the failure

Fig. 13. Effective area of the interface $\left(A_{\text {eff }}\right)$ proposed by Niwa et.al. [2] 
Table 2. Comparison of experiment and calculation.

\begin{tabular}{|l|c|c|c|c|c|}
\hline Specimen & \multirow{2}{*}{$\begin{array}{c}A_{\text {eff }} \\
\left(\mathrm{mm}^{2}\right)\end{array}$} & $\begin{array}{c}\text { Pcal } \\
(\mathrm{kN})\end{array}$ & $\begin{array}{c}\text { Pexp/ } \\
\text { Pcal }\end{array}$ & $\begin{array}{c}\text { Pcal } \\
(\mathrm{kN})\end{array}$ & $\begin{array}{c}\text { Pexp/ } \\
\text { Pcal }\end{array}$ \\
\hline SL-P1.0 & 25000 & 135.6 & 1.04 & 129.9 & 1.07 \\
\hline SL-Smooth & 30000 & 128.1 & 1.09 & 133.2 & 1.05 \\
\hline Mean & & 1.06 & & 1.07 \\
\hline \multicolumn{2}{|l|}{ Standard deviation } & & 0.03 & & 0.04 \\
\hline \multicolumn{2}{|l|}{ Coef. of Var.(C.V.) } & & 3.1 & & 3.3 \\
\hline
\end{tabular}

$A_{\text {eff: }}$ effective area of the interface; $P_{E X P}$ : ultimate capacity from experiment; $P_{C A L}$ : ultimate capacity from calculation

diagonal concrete strut, which is calculated by Eq. (6) below.

$$
v=0.55\left(30 / f_{c, \text { cube }}\right)^{1 / 3} \leq 0.55
$$

It must be noted that the design guidelines assume the area of the interface as the total area of the interface ( $A_{c}=150,000 \mathrm{~mm}^{2}$ in this study). According to the discussions in Fakhruddin et al. [3], the area of the interface should not be calculated using the total area of the interface but should be determined as the effective area $\left(A_{e f f}\right)$ as presented in Fig. 13. The $A_{\text {eff }}$, the total cross-section area of transverse rebars which have yielded at the failure $\left(A_{S}\right)$, and ultimate prestressing levels $\left(\sigma_{u}\right)$ are tabulated in Table 2.

Eventually, the predicted ultimate capacities using JSCE Specification and fib MC2010 are listed in Table 2. The results demonstrated that all the selected design guidelines provided a good lower limit for the experimental ultimate capacities. JSCE Specification gave $P_{E X P} / P_{C A L}$ that varied from 1.04 to 1.09 with a coefficient of variation (C.V.) of 3.1\% and fib MC2010 gave $P_{E X P} / P_{C A L}$ ratio that varied from 1.05 to 1.07 and C.V. of $3.4 \%$.

\section{Conclusions}

1. The roughness of the interface directly affects the first joint opening load, the joint opening at the same load level, and the deflection at the failure. The higher the roughness of a particular surface, the higher the first joint opening load and the joint opening at the same load level; and on the other hand, the smaller the deflection at the failure can be observed.

2. The variation in surface roughness of the interface does not show any remarkable influence on the ultimate capacity as long as the amount of prestressing force is sufficiently introduced to the interface. An obvious difference is only observed just before the failure, in which the shear slip occurs on the smooth surface.

3. If the prestressed concrete (PC) deck slab was supported on three-sides and subjected to a concentrated load immediately adjacent to the interface, the variation of the surface roughness does not show any remarkable influence on the ultimate capacity.
4. The effective area of the interface for the widening PC deck slabs having the rough and smooth surfaces was proposed in this study. By using the effective area of the interface instead of the total area, it has been confirmed that predicted shear capacity obtained from the guidelines provided a good lower limit for the experimental ultimate capacity.

\section{Acknowledgement}

The authors are would like to grateful to Niwa Laboratory (Tokyo Institute of Technology) and Fuji P. S. Corporation for their kind support to this research project.

\section{References}

1. Yamauchi, T., Morita, A., Sato, A., Nishinaga, T., Tokumitsu, T., Yagi, Y., Yamada, M. and Yamaguchi, M., (25 April 2016). "Widening PC floor version structure and widening construction method of established PC floor version." Japanese Unexamined Patent Application Publication No. 2016-61045.

2. Niwa, J., Fakhruddin, Matsumoto, K., Sato, Y., Yamada, Y. and Yamauchi, T., (2016). "Experimental study on shear behavior of the interface between old and new deck slabs." Engineering Structures, 126, 278-291.

3. Zhou X, Mickleborough N, Li Z. Shear strength of joints in precast concrete segmental bridges, $A C I$ Structural Journal, pp. 3-11, 2005.

4. Wakasa T, Otsuka H, Yabuki W. Experimental study of the shear strength of precast segmental beams with external prestressing, Structural Concrete, 6, No. 2, pp. 63-80, 2005.

5. Santos PMD, Júlio ENBS, Silva VD. Correlation between concrete-to-concrete bond strength and the roughness of the substrate surface. Construction Building Material, 21, No. 8, pp.1688-1695, 2007.

6. Santos PMD, Júlio ENBS. Factors affecting bond between new and old concrete. ACI Mater J, 108, No. 4, pp. 449-56, 2011.

7. Nie JG, Wang YH, Zhang XG, Fan JS, Cai CA. Mechanical behavior of composite joints for connecting existing concrete bridges and steelconcrete composite beams, Journal of Constructional Steel Research, 75, pp. 11-20, 2012.

8. Randl N. Design recommendations for interface shear transfer in fib Model Code 2010, Structural Concrete, 14, No. 3, pp. 230-241, 2013.

9. Rahal KN, Khaleefi AL, Al-Sanee. An experimental investigation of shear-transfer strength of normal and high strength self compacting concrete, Engineering Structures, 109, pp. 16-25, 2016.

10. Japan Society of Civil Engineers (JSCE): Standard specification for design of concrete structures, structure performance verification, 2012. 
11. International Federation for Structural Concrete (fib): Model code 2010, October 2013.

12. El-Gamal, S., El-Salakawy, E. and Benmokrane, B., (2007). "Influence of reinforcement on the behavior of concrete bridge deck slabs reinforced with FRP bars." J. Compos. Constr., 11, 449-458.

13. Chigira, E., Niwa, J., Tanaka, Y. and Katagiri, M., (2007). Study on punching shear resistance of the UFC panel. Proceeding of the JCI, 29, No. 3, 17411746. (in Japanese)
14. AASHTO: LRFD bridge design specifications, $4^{\text {th }}$ Edition, American Association of State Highway and Transportation Officials, 2007.

15. Randl, N.: Design recommendations for interface shear transfer in fib Model Code 2010, Structural Concrete, 14, No. 3, pp. 230-241, 2013.

16. Fakhruddin, T. Nakamura, Y. Sato, M. Yamada, and J. Niwa. Mechanical behavior of widening prestressed concrete deck slabs under concentrated load, Journal of Advanced Concrete Technology, 15, pp. 38-54, 2017. 